\title{
PENINGKATAN KUALITAS MINYAK JELANTA MENGGUNAKAN KARBON AKTIF DAN EKSTRAK PUCUK IDAT (Cratoxylum glaucum)
}

\author{
Robby Gus Mahardika ${ }^{1 *}$, Sito Enggiwanto ${ }^{1}$, Ary Samsiar ${ }^{1}$ \\ 1 Jurusan Kimia, Fakultas Teknik, Universitas Bangka Belitung \\ Jl. Kampus Peradaban, Merawang, Bangka, 33172
}

*Corresponding author: robbygusmahardika@gmail.com

\begin{tabular}{l}
\hline ARTICLE INFO \\
Article history: \\
Received 21 May \\
2018 \\
Accepted 28 May \\
2018 \\
Available online \\
26 June 2018 \\
Keywords: \\
Cratoxylum glaucum \\
Waste cooking oil \\
Activated carbon \\
\end{tabular}

\begin{abstract}
Silica Waste cooking oil can be used as a soap or biodiesel. Good soaps or biodiesel should be from oils that have low levels of fatty acids and free radicals. However, waste cooking oil has high free fatty acid and free radical, it is necessary to increase the quality of waste cooking oil. One effort to improve the quality of waste cooking oil can use activated carbon as an adsorbent. Decrease in free radicals in cooking oil can use antioxidants from extract pucuk idat (Cratoxylum glaucum). This study aims to see the effect of extract pucuk idat on the process of improving the quality of waste cooking oil. The process of improvement by adding activated carbon and varying the concentration of ethanol extract pucuk idat. Activated carbon used $10 \%$ with variation of extract $0,25 \%$; $0,5 \%$ and $0,75 \%$. This process followed by stirring for 15 minutes at $80^{\circ} \mathrm{C}$, then soaked for 3 days. Oil quality are identified by the method of determining the levels of free fatty acids and acid numbers. The results of this study indicate that extract pucuk idat in ethanol with $0,75 \%$ concentration has the lowest free fatty acid and acid number. Extract pucuk idat can improve the quality of waste cooking oil.
\end{abstract}

(C) 2018 IJoPAC. All rights reserved

\section{Pendahuluan}

Minyak goreng merupakan salah satu media pengolahan bahan makanan yang telah digunakan masyarakat secara luas khususnya di bidang industri pangan. Berdasarkan data yang di olah Gabungan Pengusaha Kelapa Sawit Indonesia (Gapki), memproyeksikan total produksi minyak goreng sawit pada tahun 2017 meningkat menjadi 38,7 juta ton[1]. Kebutuhan minyak goreng dari tahun ke tahun yang meningkat serta semakin bertambahnya jumlah penduduk dan produksi minyak, hal ini memungkinkan semakin banyak minyak jelantah yang dihasilkan.

Minyak jelantah merupakan limbah rumah tangga atau industri gorengan yang mempunyai kadar asam lemak bebas dan radikal bebas yang tinggi. Jika dikonsumsi dan digunakan terus menerus minyak ini bersifat karsinogen sehingga sangat berbahaya bagi tubuh. Minyak jelantah sendiri dapat dimanfaatkan sebagai sabun, biodisel, dan minyak goreng kembali [2]. Untuk dapat dimanfaatkan sebagai bahan biodisel dan minyak goreng kembali minyak jelantah harus mempunyai kadar asam lemak bebas dan radikal bebas yang rendah. Minyak jelantah yang dapat menjadi bahan baku biodiesel memiliki kadar asam lemak bebas dibawah 5\%, kadar air dibawah $2 \%$, dan bersih dari sisa bahan gorengan[3]. Sedangkan jika digunkan sebagai minyak goreng kembali, minyak jelantah harus memenuhi SNI minyak goreng dengan kadar asam lemak 
bebas tidak boleh lebih dari $0,3 \%{ }^{[4]}$. Oleh sebab itu perlu dilakukan upaya peningkatan kualitas minyak jelantah yang mempunyai kualitas yang buruk

Metode membran dan adsorbsi telah banyak digunakan sebagai peningkatan kualitas minyak jelantah. Adsorbsi menjadi metode yang banyak digunakan dalam peningkatan minyak jelantah, metode ini menggunakan adsorben mulai dari ampas tebu, arang aktif, kulit pisang, buah mengkudu dan lain-lain[5],[6].[7]. Karbon aktif masih menjadi salah satu adsorben yang terbaik dalam proses ini. Adsorben ini dapat mengadsorbsi radikal bebas dan sisa-sisa penggorengan. Salah satu langkah untuk mengurangi keberadaan radikal bebas dalam minyak jelantah yaitu dengan antioksidan. Senyawa yang bersifat sebagai antioksidan dapat menghambat reaksi oksidasi, dengan mengikat radikal bebas dan molekul yang sangat reaktif[8]. Dengan adanya antioksidan dalam minyak jelantah harapannya dapat mengurangi radikal bebas.

Senyawa antioksidan dapat berupa senyawa flavonoid, tanin, antrakuinon dan santon banyak ditemukan pada tanaman pucuk idat (Cratoxylum glaucum)[9]. Spesies Cratoxylum glaucum merupakan tanaman endemik Bangka Belitung, dikenal dengan nama "Pucuk Idat". Pucuk Idat sangat dikenal oleh masyarakat Bangka Belitung karena sering dimanfaatkan sebagai penyedap masakan. Pemanfaatan bagian batang, akar, daun dan kulit batang Cratoxylum glaucum sebagai obat tradisional telah lama digunakan oleh masyarakat. Daun Cratoxylum glaucum biasanya digunakan sebagai penyedap masakan. Bagian lainnya sebagai obat tradisional untuk memperlancar ASI, mengencangkan kulit, mengobati demam, batuk, diare dan penyakit lainnya[10].



Gambar 1. Daun pucuk idat (Cratoxylum glaucum)

Berikut ini adalah taksonomi dari Cratoxylum glaucum:

$\begin{array}{ll}\text { Kingdom } & : \text { Plantae } \\ \text { Ordo } & : \text { Malpighiales } \\ \text { Famili } & : \text { Hipercaceae } \\ \text { Genus } & : \text { Cratoxylm } \\ \text { Spesies } & : \text { Cratoxylum glaucum }\end{array}$

Kajian fitokimia dan aktivitas terhadap ekstrak atau senyawa metabolit sekunder Cratoxylum glaucum masih sangat sedikit. Sedangkan spesies ini sangat sering digunakan oleh masyarakat sebagai obat tradisional. Oleh sebab itu penelitian ini bertujuan untuk melihat pengaruh antioksidan ekstrak pucuk idat (Cratoxylum glaucum) pada proses peningkatan kualitas minyak jelantah menggunakan karbon aktif.

\section{Metode Penelitian}

\subsection{Preparasi Sampel}

Daun pucuk idat (Cratoxylum glaucum) yang digunakan dalam penelitian ini berasal dari Desa Sempan, Kecamatan Pemali, Kabupaten Bangka. Selanjutnya sampel tersebut akan dikeringkan di udara terbuka, setelah itu diblender menjadi serbuk kering yang selanjutnya siap untuk dimaserasi. 
Serbuk kering daun Pucuk idat (Cratoxylum glaucum) diambil 65 gram kemudian dimaserasi dengan pelarut etanol sebanyak $325 \mathrm{~mL}$ selama 2x24 jam. Maserasi dilakukan dua kali. Setelah itu dipisahkan antara filtrat dengan residu menggunakan corong buchner. Filtrat yang diperoleh dipekatkan dengan rotary evaporator vacum hingga diperoleh ekstrak pekat etanol [11].

\subsection{Identifikasi Metabolit Sekunder}

Identifikasi metabolit sekunder terhadap ekstrak etanol kering dilakukan secara kualitatif dari daun pucuk idat (Cratoxylum glaucum). Identifikasi dilakukan di Laboratorium MIPA FPPB UBB.

Identifikasi senyawa alkaloid. Ekstrak kasar ditambah 0,5 mL HCl $2 \%$, selanjutnya larutan dibagi dalam dua tabung. Tabung I ditambahkan 2-3 tetes reagen Wagner, tabung II ditambahkan 2-3 tetes reagen Mayer. Identifikasi senyawa fenol hidrokuinon (tanin). $50 \mathrm{mg}$ ekstrak metanol, etil asetat, atau etanol dilarutkan dalam $5 \mathrm{~mL}$ etanol pro analis (p.a) dan ditambahkan 3 tetes larutan $\mathrm{FeCl}_{3}$. Identifikasi senyawa flavonoid. Metode pengujian yang dilakukan dengan uji Wilstater sianidin dengan cara ekstrak dilarutkan dalam 1-2 mL metanol panas $50 \%$, kemudian ditambah logam $\mathrm{Mg}$ dan $0,5 \mathrm{~mL} \mathrm{HCl}$ pekat. Identifikasi senyawa saponin. Ekstrak ditambahkan $5 \mathrm{~mL}$ aquadest panas. Kemudian didinginkan dan dikocok selama 10 menit. Hasil positif ditunjukkan dengan terbentuknya busa atau buih dan pada penambahan 1 tetes asam klorida $2 \mathrm{~N}$ buih tidak hilang. Identifikasi senyawa terpenoid dan steroid Ekstrak kasar diambil dan dilarutkan dengan kloroform sebanyak 0,5 mL, lalu ditambah dengan 0,5 $\mathrm{mL}$ anhidrida asetat. Selanjutnya ditambah dengan 1-2 mL $\mathrm{H}_{2} \mathrm{SO}_{4}$ pekat melalui dinding tabung tersebut[12].

\subsection{Preparasi Minyak Jelantah}

Minyak jelantah yang diperoleh dari limbah rumah tangga wilayah Pangkal Pinang dan diambil 3 sampel dimana sampel pertama sebagai pembanding dengan banyak minyak masingmasing sampel 20 gram. Proses selanjutnya minyak ditambahkan dengan $10 \%$ karbon aktif dengan variasi pucuk idat 0,25\%, 0,5\% dan 0,75\% kemudian lakukan pengadukan menggunakan hotplate stirer selama 15 menit pada suhu $80^{\circ} \mathrm{C}$. Minyak tersebut selanjutnya disimpan selama 3 hari. Langkah selanjutnya minyak jelantah disaring menggunakan corong buhcner. Minyak ini selanjutnya dilakukan pengujian kualitas minyak dengan metode uji meliputi kadar asam lemak bebas, uji bilangan asam.

\subsection{Uji Kadar Asam Lemak Bebas}

Kadar asam lemak bebas (FFA) dilakukan dengan mengabil 1 gram minyak dan ditambahkan $25 \mathrm{ml}$ etanol 95\% dilarutkan dengan cara menggoyangkan erlenmeyer. Kemudian


warna merah muda tetap (tidak berubah selama 30 detik). Kadar asam lemak bebas yang terkandung dalam minyak dihitung dengan menggunakan persamaan 1 [13].

$$
\begin{aligned}
& \text { Kadar asam lemak bebas }=\frac{\mathrm{N} \times \mathrm{A} \times \mathrm{N}}{10 \mathrm{G}} \\
& \text { Keterangan: } \\
& \mathrm{M} \quad=\text { berat molekul asam lemak, yaitu } 263 \\
& \mathrm{~N} \quad=\text { normalitas larutan } \mathrm{KOH} \\
& \mathrm{A} \quad=\text { volume ml KOH } \\
& \mathrm{G} \quad=\text { berat sampel (gram) }
\end{aligned}
$$




\subsection{Uji Bilangan Asam}

Sebanyak 1 gram minyak ditambahkan $10 \mathrm{~mL}$ alkohol 95\%. Selanjutnya dipanaskan selama 10 menit. Kemudian ditambahkan 3 tetes indikator fenolftalein dan dititrasi dengan $\mathrm{KOH} \mathrm{0,01} \mathrm{N}$ hingga terbentuk warna merah muda. Nilai bilangan asam dihitung dengan persamaan 2 [13].

$$
\begin{aligned}
& \% \text { Bilangan Asam }=\frac{A \times N ~ K O H ~ x ~ 56,1}{m} \\
& \text { Keterangan: } \\
& A=\text { volume larutan } \mathrm{KOH} \\
& \mathrm{N}=\text { Normalitas } \\
& \mathrm{M}=\text { massa contoh minyak (gram) }
\end{aligned}
$$

\section{Hasil dan Pembahasan}

Proses ekstraksi pada penelitian menggunakan metode maserasi dengan pelarut etanol. Metode maserasi sendiri merupakan metode ekstraksi cara dingin yang sederhana. Prosedur yang dilakukan dengan merendam bahan tanaman dalam pelarut yang sesuai yang kemudian ditutup pada suhu ruangan, harapannya penggunaan metode ini tidak merusak senyawa dari pucuk idat sendiri. Penggunaan pelarut etanol yang bersifat semipolar harapannya dapat mengekstrak metabolit sekunder yang bersifat polar maupun non polar[14]. Ekstrak tersebut yang selanjutnya akan dilakukan identifikasi metabolit sekunder.

Kandungan senyawa yang ada pada ekstrak pucuk idat (Cratoxylum glaucum) dianalisis golongan metabolit sekunder didalamnya dengan beberapa uji kualitatif. Uji ini menggunakan beberapa pereaksi untuk mengidentifikasi golongan senyawa alkaloid, fenol hidrokuinon, flavonoid, saponin dan steroid. Hasil identifikasi metabolit sekunder disajikan dalam Tabel 1.

Tabel 1. Identifikasi metabolit sekunder ekstrak etanol pucuk idat (Cratoxylum glaucum)

\begin{tabular}{lllc}
\hline \multirow{2}{*}{ Uji } & \multicolumn{1}{c}{$\begin{array}{c}\text { Metode } \\
\text { Pengujian }\end{array}$} & \multicolumn{1}{c}{ Hasil } & Ket. \\
\hline Alkalaoid & Mayer & $\begin{array}{l}\text { Terbentuk endapan } \\
\text { putih kekuningan }\end{array}$ & + \\
\cline { 2 - 4 } & Wagner & $\begin{array}{l}\text { Terbentuk endapan } \\
\text { coklat }\end{array}$ & + \\
\hline $\begin{array}{l}\text { Fenol } \\
\text { Hidrokuinon } \\
\text { (Tanin) }\end{array}$ & $\mathrm{FeCl}_{3}$ & $\begin{array}{l}\text { Terbentuk warna hijau } \\
\text { atau hijau biru }\end{array}$ & + \\
\hline Flavonoid & $\begin{array}{l}\text { Uji Wilstater } \\
\text { sianidin }\end{array}$ & $\begin{array}{l}\text { Terbentuk warna } \\
\text { jingga. }\end{array}$ & + \\
\hline Saponin & Uji Forth & Tidak ada busa & - \\
\hline $\begin{array}{l}\text { Terpenoid dan } \\
\text { Steroid }\end{array}$ & $\begin{array}{l}\text { Uji } \\
\text { Liebermann- } \\
\text { Burchard }\end{array}$ & $\begin{array}{l}\text { Terbentuk warna biru } \\
\text { dan hijau }\end{array}$ & + \\
\hline
\end{tabular}

Berdasarkan data penelitian yang disajikan pada tabel 2, kadar asam lemak bebas kontrol dan bilangan asam mempunyai nilai 1,104 \% dan 1,290 \%. Nilai tersebut sangat tinggi jika dibandingan setelah penambahan ekstrak pucuk idat dan karbon aktif. Penambahan ekstrak 
pada konsentrasi $0,75 \%$ mempunyai nilai yang paling rendah dibandingkan yang lain. Data tersebut menunjukkan bahwa semakin tinggi konsentrasi ekstrak pucuk idat akan mengakibatkan penurunan kadar asam lemak bebas dan bilangan asam. Ekstrak etanol pucuk idat sebagai antioksidan pada proses ini menghambat oksidasi dan hidrolisis trigliserida. Hal ini berawal dari penghambatan pembentukan peroksida dari asam lemak. Peroksida yang terbentuk distabilkan oleh antioksidan melalui donor atom hidrogen[15], sehingga dapat mencegah proses oksidasi maupun hidrolisis pada minyak. Jika proses hidrolisis tersebut dihambat, maka kadar asam lemak bebas yang menggunakan ekstrak menjadi lebih rendah daripada kontrol.

Tabel 2. Hasil uji kualitas minyak jelantah

\begin{tabular}{cccc}
\hline $\begin{array}{c}\text { Karbon } \\
\text { Aktif (\%) }\end{array}$ & $\begin{array}{c}\text { Ekstrak Pucuk } \\
\text { Idat (\%) }\end{array}$ & $\begin{array}{c}\text { Asam Lemak } \\
\text { Bebas (\%) }\end{array}$ & $\begin{array}{c}\text { Bilangan Asam } \\
(\%)\end{array}$ \\
\hline \multirow{2}{*}{10} & 0,25 & 0,959 & 1,122 \\
& 0,50 & 0,894 & 1,093 \\
Kontrol $^{*}$ & 0,75 & 0,854 & 0,897 \\
\hline \multicolumn{4}{c}{${ }^{*}$ ) sampel minyak jelantah (karbon aktif $=0$; ekstrak $=0$ ) }
\end{tabular}

Pengaruh ekstrak terhadap nilai asam lemak bebas dan bilangan asam disajikan pada gambar 1. Meskipun ada kecenderungan bertambahnya konsentrasi ekstrak mengakibatkan penurunan asam lemak bebas dan bilangan asam, tetapi kecenderungan tersebut tidak mangakibatkan penurunan yang signifikan.

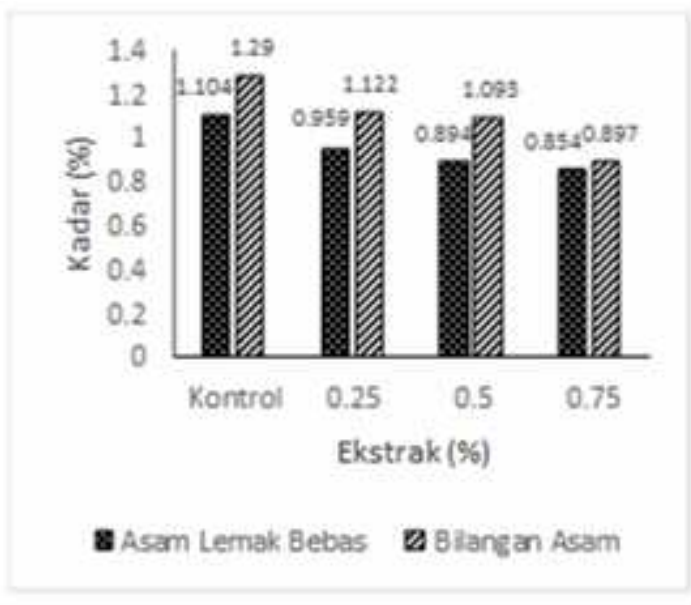

Gambar 2. Pengaruh ekstrak idat terhadap asam lemak bebas

Penggunaan karbon aktif pada penelitian ini membantu menyerap sisa-sisa hasil penggorengan yang dapat berupa polimer hasil penggorengan, asam lemak bebas, dan zat-zat lainnya[3]. Hal ini ditunjukkan dari nilai asam lemak bebas dan bilangan asam kontrol yang berbeda hingga lebih dari 0,14\% jika dibandingkan dengan konsentrasi ekstrak 0,25\%. 


\section{Kesimpulan}

Berdasarkan penelitian yang telah dilakukan bahwa penambahan ekstrak pucuk idat (Cratoxylum glaucum) berpengaruh pada kadar asam lemak bebas dan bilangan asam. Penggunaan ekstrak pucuk idat pada konsentrasi 0,75\% mempunyai kadar asam lemak bebas $0,854 \%$ dan bilangan asam $0,857 \%$. Nilai tersebut merupakan nilai yang paling rendah dibandingkan dengan variasi konsentrasi ekstrak lainnya.

\section{Ucapan Terima Kasih}

Peneliti mengucapkan terima kasih kepada Rektor Universitas Bangka Belitung yang telah memberikan bantuan dana penelitian berdasarkan SK Rektor No. 1348/UN50/PL/2017.

\section{Referensi}

[1]. Hajar, E.W.I. \& Mufidah, S., 2016. Penurunan Asam Lemak Bebas pada Minyak Goreng Bekas Menggunakan Ampas Tebu untuk Pembuatan Sabun. Jurnal Integrasi Proses,6: pp. 22-27.

[2]. Aziz, I., Nurbayti, S. \& Ulun, N.,2011, Pembuatan Produk Biodiesel dari Minyak Goreng Bekas dengan Cara Esterifikasi dan Transesterifikasi. Jurnal Valensi, 2: pp. 443-448.

[3]. Asthasari, R.U., 2008. Kajian Proses Pembuatan Biodiesel Dari Minyak Jelantah Dengan Menggunakan Katalis Abu Tandan Kosong Sawit. [Skripsi]. Bogor. Institut Pertanian Bogor.

[4]. Putra, A., Mahardania, S., Dewi, A. \& Saptia, E., 2012. Recovery Minyak Jelantah Menggunakan Mengkudu sebagai Absorben. Malang: Prosiding Seminar Nasional PERTETA.

[5]. Aisyah, S., Yulianti, Eny \& Fasya., A.G., 2012. Penurunan Angka Peroksida dan Asam Lemak Bebas (FFA) pada Proses Bleaching Minyak Goreng Bekas oleh Karbon Aktif Polong Buah Kelor (Moringa Oliefera Lamk.) dengan Aktivtas NaCl. Alchemy, 13: pp. 93103.

[6]. Ramdja, F.A., Febrina, L. \& Krisdianto, D., 2010. Pemurnian Minyak Jelantah Menggunakan Ampas Tebu sebagai Adsorben. Jurnal Teknik Kimia, 17: pp. 7-14

[7]. Winarsi, H., 2007. Antioksidan Alami dan Radikal Bebas. Yogyakarta: Kanisius.

[8]. Yap, Rahmani M., \& Taufiq Y.H., 2007. Compounds From Cratoxylum aborescens, Cratoxylum glaucum, Garcinia nitida and Garcinian mangostana and their Potential as Anti-Cancer Lead Compounds. Pertanika Journal of Science \& Technology, 1: pp. 43-47.

[9]. Yingngam, B., Supaka N., \& Rungseevijitprapa, W., 2014. Optimization of Process Condition for Phenolics Extraction from Cratoxylum formosum ssp. formosum leaves using response surface methodology. Asian Pacific Journal of Tropical Medicine, 7: pp. 497-505.

[10]. Dungir, S.G., Khanuja, S.P.S., Longo, G. \& Rakes D.D., 2012. Aktivitas Antioksidan Ekstrak Fenolik dari Kulit Buah Manggis (Gracinia Mangostana L.). Jurnnal MIPA UNSTRAT Online 1, 1 (1): pp. 11-15.

[11]. Marlinda, M. S. M. W. A., 2012. Analisis Senyawa Metabolit Sekunder dan Uji Toksisitas Ekstrak Etanol Biji Buah Alpukat (Persea americana Mill.). Jurnal Kimia Unstrat, 1, pp. 24-28.

[12]. Lempang, R., I., Fatmawali, \& Nancy, C.P., 2016. Uji Kualitas Minyak Goreng Curah dan Minyak Goreng Kemasan di Manado. Pharmacon, 5: pp. 155-161. 
[13]. Handa, S.S., Khanuja S.P.S., Longo, G. \& Rakes, D.D., 2008. Estraction Technologies for Medicinal and Aromatic Plant. Trieste: International Center for Science and High Technology.

[14]. Cikita, I., Hasibuan, I.H. \& Hasibuan, R., 2016. Pemanfaatan Flavonoid Ekstrak Daun Katuk, (Sauropus androgymus L Merr) Sebagai Antioksidan Minyak Kelapa. Jurnal Teknik Kimia USU, 5: pp. 45-51. 